\title{
MINERIA PERUANA Y REFORMISMO ESTATAL: LAS ORDENANZAS DEL REAL BANCO DE SAN CARLOS DE LA VILLA DE POTOSI
}

\section{INTRODUCCIÓN}

Durante la segunda mitad del siglo XVIII, la actividad extractiva del cerro de Potosí seguía siendo considerada como el principal filón minero del virreinato peruano, a pesar de la pérdida del esplendor que había protagonizado en los primeros momentos de su explotación, y que le habían valido la admiración de observadores y cronistas. ' "Aunque Potosí no ocupara más un lugar de primer orden en la economía mundial, su producción era fundamental para la articulación de un extenso espacio económico sudamericano. Hacia mediados de la década de 1770 equivalía al $40 \%$ de la plata producida en todo el virreinato del Perú». ${ }^{2}$

A pesar de este destacado saldo productivo, la minería se veía afectada por una serie de trabas y dificultades endémicas, que no hacían sino incrementar el alto grado de riesgo inherente a ella.

«...una mina está sugeta a varios contratiempos como son, el perderse la veta, el escasear el metal, el aguarse con demasía, o hacerse algún derrumbe considerablem. ${ }^{3}$

1 Cieza de León, P.: La Crónica del Perú. Ed. de Manuel Ballesteros. Madrid, 1984, pág. 374.-De Santacilia, Jorge Juan y Ulloa, Antonio de: Noticias Secretas de América. Madrid, 1982, vol. II, pág. 543 (2 vols.).-Cañete y Dominguez, P. V.: Guía histórica, oeooráflca, política, civil y leoal del Gobierno e Intendencia de Potosí. Potosí, 1952.-Arzáns de Ursúa: Historia de la Villa Imperial de Potosí. Ed. de L. Hanke y G. Mendoza. 3 vols. Providence, 1065.

2 Tandeter, E.: Trabajo forzado y trabajo libre en el Potosi colonial tardio. Estudios CEDES. Buenos Aires, 1980, núm. 6, pág. 5.

3 De Santacilia y Ulloa: Noticias Secretas.... pág. 560. 
La ineludible exigencia de hacer frente a estos obstáculos, junto a los derivados de la baja ley de los metales, ${ }^{4}$ los altos costos en adquisición de insumos, transporte del mineral a las plantas de beneficio y exacciones fiscales, situaba a los azogueros ante una constante demanda de capital.

La situación efectiva de los mineros en el Perú colonial aparece reflejada en varios testimonios de la época. ${ }^{5}$ «Ruinoso estado de las minas, metalurgia ineficiente, capitalización rudimentaria, éstos eran los tres problemas estructurales de la minería de Potosí»" hacia los que habrá de canalizar su interés el Estado reformista.

Los objetivos de la política borbónica aplicada a la minería estuvieron dirigidos al incremento de la producción y el rendimiento económico, para los cuales se pondrían en marcha medidas tendentes a la restricción de costos, reducción de impuestos e implantación de nuevas técnicas. ${ }^{7}$ Como actividades complementarias, se procedió a actualizar los códigos legales mineros, mostrando especial interés en agilizar los procedimientos judiciales y favorecer en lo posible a los mineros, dignificando socialmente su profesión y potenciando su actividad mediante la concesión de diversas ventajas.

Rescatar a los mineros de las relaciones de dependencia del capital usurario y la ambición de los comerciantes se erigió en aspi-

4 Archivo General de Indias. (En adelante A.G.I.), Lima, 1.091. Ordozgoiti a Escobedo: aLos metales encontrados hasta aquí (...) son de corta ley, y of recen mucha pérdida (...) pues escasamente llegan a rendir, por hornada una arroba...». Huancavelica, 6 de julio de 1782.

5 Real Academia de la Historia, Colección Mala Linares. (En adelante. R.A.H., ML), tomo LXIX. Manrique a Escobedo. Potosí, 17 de julio de 1783. Relaciones de los Virreyes y Audiencias que han gobernado el Perú. Madrid, 1872 (4 vols.). Vol. III: «Oflcio escrito al Excmo. Sr. D. Joseph de Gálvez sobre la conclusión de la Visita de estos Reinos. Año de 1785», pág. 416.

6 Arduz Eguía, G.: Ensayos sobre la Historia de la minería altoperuana. Madrid, 1985, pág. 111.

7 Pérez de Tudela y Bueso. J.: Acerca del significado de Túpac Amaru en la Historia Politica de la Monarquía Indiana. \&V Congreso Internacional de Historia de América», tomo II. Lima, 1972. Ver: «Instrucción que debe observar D. José Antonio de Areche en la Visita y arreglo de los Tribunales de Cuentas... en los Reinos del Perú, Chile y Provincias del Rio de la Plata». Art. 37, pág. 471: «Como la Villa de Potosí, por su situación, riqueza de sus minerales (...) sea el centro y corazón del Reino que vivifica aquel vasto cuerpo, será conveniente... actuar aquella visita (...) enteraros de cuanto convenga proveer al mejor régimen, gobierno y mayor aumento de los Ramos de mi Real Hacienda». Madrid, 20 de junio de 1776. 
ración primordial de la comisión de la visita general enviada a la villa minera, marco en el que iban a inscribirse una serie de importantes medidas de fomento de la actividad extractiva. Don Jorge Escobedo y Alarcón, oidor de la Audiencia de Charcas, fue el funcionario elegido para desempeñar la difícil misión de imponer racionalidad en las actividades de la villa. ${ }^{8}$ "Ningún lugar del Reino necesitaba tanto como Potosí el establecimiento de un fondo público, para prosperidad del país, para conveniencia de los mineros y para ventaja de la Real Hacienda; porque sólo por este medio podía lograrse que se aumentase la masa circulante de los valores efectivos y numerarios, con los que, además de vivificar el comercio y socorrer la industria de la minería, se hace de presente y sin fraude el pago de los Rs. Derechos». ${ }^{9}$

En efecto, desde el establecimiento de la Compañía de Azogueros de Potosí el 12 de enero de 1747 y su transformación, a instancia del visitador de las Cajas Reales don José de Herboso, en Banco de Rescates el 7 de febrero de 1752, no habían dejado de producirse violentas tensiones entre administradores y mineros, que ponían en peligro la existencia de la institución. "10

Los nutridos fondos con que se iniciaron las administraciones de San Just (1762-1767), Alvarez de Acevedo (1773) y el conde de San Antonio (1773-1777), fueron dilapidados por la irreflexiva práctica de conceder préstamos sin garantía y respaldar con ellos

8 A.G.I., Buenos Aires, 354. «Instrucción de Gobierno que V.M. manda observar a D. Pedro Cevallos... sobre el mando político y económico de las Provincias del Río de la Plata. San Ildefonso, 15 de agosto de 1776. Art. 11: Nombramiento de D. Jorge Escobedo como comisionado a la Villa de Potosí. Ibídem. 7. Libro I. fols. 1-1v. Gálvez a Miguel San Martín Cueto. 29 de marzo de 1778. Se señalan las facultades plenas de Escobedo en la villa...-Pérez de Tudela: Acerca del sionificado de Túpac Amaru... «Instrucción...», pág. 475. Art. 45: «... conservar, aumentar y proteger tan útil establecimiento (el Banco).... y enterado de las diversas... vicisitudes... procuraréis arreglar de un modo sencillo, fácil y de poco embarazo, la administración de estos caudales, el giro de ellos y las precauciones de seguridad para su manejo, tirando a precaver los inconvenientes que han resultado de su mala administract6n...s.

9 Cañete: Guia histórica, geográfica, política.... cap. 7. pág. 125.

10 Rodríguez Casado, V. y Pérez Embid, F.: Memoria de Gobierno del Virrey Amat (1761-1776). Sevilla, 1947, pág. 667: \&... a tin de que subsista tan importante establecimiento, y más si se considera la decadencia en que se halla el Mineral de Potosi (...), principal fuente que riega y fecunda el Reyno y de quien pende su conserbación (sic)...». 
deudas particulares. Unido a cllo, el afán de lucro personal les llevó a la especulación con los caudales del Banco, actividad que supieron compaginar con el ejercicio, más o menos honrado y eficaz, de su autoridad en Potosí. Las profundas quiebras que resultaron de estas actividades, hubieron de ser paliadas por sus sucesores: Santelices (1751-1762), Tagle (1767-1773) y Güemes (estos últimos partidarios convencidos de la incorporación del Banco a la Corona), a través de una gestión de fuertes restricciones, siempre protestada por los mineros, que permitió vivir momentos de efímero esplendor en las arcas del Banco.

A pesar de ello, la situación se agravaba paulatinamente. Continuaban los negocios con los caudales del erario, y la lentitud de la Casa de Moneda en atender las labores de acuñación causaba graves demoras en el envío del «situado» a Buenos Aires, donde se vivía el momento más álgido de la guerra con Portugal por la colonia de Sacramento. "La necesidad de una solución a tal cúmulo de problemas se hacía cada vez más acuciante, y vino dada por la comisión de visita.

\section{FunCiones y PRERroghtivas DEL BANCO de Rescates de Potosí}

El Banco de Rescates había sido instituido como entidad para fomentar la azoguería. Sostenido por los propios mineros, que entrcgaban 2 pesos $3 / 4$ reales del valor de cada marco rescatado, el fondo acopiado se destinaba a la habilitación de sus operaciones: dotación de azogue, hierro, ejes, madera, y todo tipo de materiales para el laboreo a precios asequibles. «...Algunas substancias como las salinas o el carbón no fueron objeto de regulación uniforme», ${ }^{12}$

11 Buechler, R. M.: La Compañia de Azogueros y el Banco de Rescates de Potosi (1747-1779). «Boletín del Instituto de Historia Argentina y Americana», número 26, vol. XVI, año XVI. Buenos Aires, 1980, págs. 67-116.-Cañete: Guía histórica, geográfica, politica..., cap. 7.

12 Alonso Rodríguez-Rivas, D.: La legislación minera hispano-colonial y la intrusión de labores. «La Minería Hispana e Iberoamericana», vol. I, León, 1970, pág. 664 . 
pero no por ello habrían de quedar olvidadas por el comisionado, agudo observador de la realidad a la que se hubo de enfrentar. ${ }^{13}$

En la misma dimensión de banco de avío, otorgaba créditos al gremio de azogueros, y tenía estipuladas una serie de ayudas financieras gracias a las cuales muchos de ellos podían hacer frente al pago de los arriendos de sus «ingenios». ${ }^{14}$

Entre sus responsabilidades se encontraba, además, la financiación de empresas de mejoramiento técnico: el famoso socavón, las lagunas de la ribera, la construcción de los barriles de la misión Weber (segmento potosino de la expedición Nordenflycht), etc.

Esta combinación de funciones, inexistente en las instituciones de otras áreas coloniales, constituyó una de las principales características del banco potosino.

Desde siempre, la obtención de capital para esta serie de operaciones había estado controlada por los «aviadores», comerciantes locales con los que el gremio minero estaba perennemente endeudado a cuenta de los créditos recibidos y a quienes en pago de los mismos malvendían sus «piñas», las cuales recorrían después diversas vías fraudulentas eludiendo el pago de los reales derechos. ${ }^{13}$

La creación del Banco pretendía el ejercicio de un monopolio en la venta de insumos y en el rescate de las platas, para las que sc establecía un mercado rápido y estable.

Con su incorporación a la Corona, ${ }^{16}$ se buscaba imponer un control por parte del Estado tanto en las operaciones como en los beneficios, logrando la erradicación del contrabando y una percepción fiscal más eficaz.

Estos objetivos debían romper con una situación crítica con-

13 British Library, Mss. Add. 13.983, fols. 95-96. Escobedo al Visitador General sobre la exención de la alcabala en carbón, lef̂a y sal, equiparándolos con los comes. tibles de primera necesidad. Potosí, 29 de abril de 1780.

14 Tandeter: Propiedad y oestión en la minería potosina de la seounda mitad del siglo XVIII. «Actas del VII Simposio Internacional de Historia económica». CLASO/IEP. Lima, 25-30 de junio de 1986, págs. 1-36.

15 Mariscal Romero, P.: Los Bancos de rescate de platas. «Estudios Americanos», tomo XX. Sevilla, 1963, pág. 315.

16 Palacio Atard, V.: La incorporación a la Corona del Banco de Rescates de Potosi. «Anuario de Estudios Americanos», vol. II, Sevilla, 1945, pács. 723-738. 
solidada por la venalidad de los administradores, la resistencia de los mineros a la exacción continua del real en marco, la escasez en la provisión de azogues, que entorpecía las operaciones de beneficio, rescate y amonedación, y la dilapidación de los fondos del banco en préstamos e inversiones incontroladas. La historia del banco, desde su fundación, está marcada por una sucesión de períodos de auge e inmediato hundimiento. Entre las quejas presentadas por los mineros, figuraba la de la inexistencia de una reglamentación concreta para el funcionamiento del Banco de Rescates que, encomendada a un tal Ezcurruchea, no fue nunca llevada a cabo.

A fines de 1770, Pedro de Tagle, oidor comisionado paral la averiguación de los abusos existentes, formó un reglamento que estuvo en vigor, presumiblemente, hasta 1777, y que dio positivos resultados. Sin embargo, cuando Escobedo se hizo cargo del gobierno del banco, recibió un fondo de 895.283 pesos que, gravado por un elevado donativo a Buenos Aires y una serie de débitos pendientes, se reducía a una mera cifra teórica.

Al parecer, la reglamentación de Tagle, considerada como el precedente directo de la del nuevo comisionado, no tuvo plasmación escrita ni carácter permanente, y recogía exclusivamente disposiciones de tipo económico no basadas en leyes, sino en la prudencia y arbitrio legal del oidor. ${ }^{17}$

Las ordenanzas formadas por Jorge Escobedo, inspiradas en las Leyes de Indias y las Ordenanzas de Minería mexicanas, se agrupaban en 14 títulos y constaban de 174 disposiciones, además de varios modelos finales para la formación de cuentas. Con ellas, tras varias décadas de funcionamiento anárquico, se dotaba al Banco de un respaldo legal que habría de dirigir todas sus labores para bien de los mineros, felicidad del público y utilidad de la Real Hacienda.

Pasemos al análisis de su contenido.

17 Buechler: La Compañía de Azogueros..., pág. 114. Cañete: Giuia histórica, geográfica, política.... pág. 131 . 


\subsection{El rescate de platas}

La ordenanza se iniciaba con una serie de consideraciones generales sobre los ministros, sus categorías y honores, reflejados en el título $1^{\circ}$, en el que se estipulaba la prohibición de que manejasen los fondos reales para negocios de carácter particular e intervinieran en actividades mineras $u$ otras ocupaciones extrañas al cargo, ${ }^{18}$ en un intento por evitar abusos derivados de ello ya sentidos en anteriores etapas de la vida del banco.

La actividad primordial de la institución, el rescate de la plata, se organizaba en el título 2..$^{\circ}$. El Banco quedaba abierto al servicio de todos los minerales, y no sólo a los del Cerro, indicio de que la comisión del visitador había sido concebida con carácter general, dirigida a beneficiar la actividad minera en la jurisdicción del virreinato, si bien los azogueros de Potosí mantenían su posición privilegiada ante las leyes. ${ }^{19}$

A lo largo del articulado, se detecta un marcado interés por centralizar la producción a través de una entidad única, evitanto así la dispersión de la plata por vías ilegales y la consiguiente evasión de impuestos.

La no exclusión de platas no impediría, sin embargo, que al rescate se realizara con distintos precios en función de las calidades del mineral y la categoría social del minero, condiciones que iban asociadas. Los tipos recogidos por la ordenanza, azogueros de Potosí, mineros de afuera, capchas y trapicheros, recibirían por sus «piñas», una vez calculada su ley por el administrador, 7 ps. y 4 rs. (en ley de 11 dineros 20 granos) los primeros, entre 7 ps. y 7 ps. y 4 rs. los segundos, y 7 ps. 1 real los terceros, ${ }^{20}$ siendo de 6 ps. y 6 rs. en el caso de los minerales de Porco, de muy baja calidad.

18 R.A.H. ML, tomo VII, fols. 78-171. Testimonio de las Ordenanzas del Banco de San Carlos de la Villa de Potosí formadas por el Sr. D. Jorge Escovedo... a la que se hallan unidos varios Modelos para el Arreglo de su Giro. Pormación de Cuent/s, etc. Potosí, enero de 1780.

19 Recopilacıón de Leyes de Indias. Madrid, 1943. 3 vols. Libro IV, tít. XX. leyes 3 y 7. Disposiciones Complementarias a las Lepyes de Indias. Madrid, 1930. 4 vols. Vol. III. Minas, núm. 756.

20 R.A.H. ML. Testimonio de las Ordenanzas del Banco..., tít. 2.", Ordenanzas $3.1,4 .{ }^{\mathrm{a}}$ y $5 .{ }^{\mathrm{a}}$ 
Resulta anómalo que se asociaran los metales de mayor lcy con la extracción llevada a cabo por los azogueros pues, aunque mejor beneficiados que los de los capchas, habían abandonado la explotación de las vetas para dedicarse a los relaves y escombreras, mientras éstos, bien por su pericia en detectar las vetas de mineral más rico, bien por la extracción del existente en los pasajes y puentes que aseguraban las galerías, obtenían plata mucho más pura. ${ }^{21}$ La explicación debe buscarse en el rechazo de que los capchas eran objeto por parte de los mineros, siempre quejosos de sus actividades de robo de mineral y destrozos que causaban en la estructura de las minas. ${ }^{22}$

Otorgando mejores precios a los azogueros, distinguiéndolos en posición social frente a los capchas, el visitador pretendía, sin renunciar a la producción de ninguno de ellos, fomentar la cxplotación legal y ordenada del Cerro, y recompensar las tareas de profundización en vetas poco accesibles en aras de un progreso tócnico de la minería. Si el azoguero encontraba una compensación económica a sus esfuerzos, se vería alentado a intentar nuevas incursiones, asumir los riesgos que implicaban y aventurarse a incrementar la producción de plata, aunque el banco hubiese de respaldarle con créditos.

A la vez, un menor precio en la plata producto del capcheo, podría actuar como factor disuasorio de dicha actividad, la claal, salvo en la percepción de diezmos por barral para la Real Hacienda, en nada beneficiaba a la azoguería. De hecho, cuando Escobcdo estipule las condiciones de crédito, excluirá sistemáticamente a los capchas de todo tipo de ayuda.

La misma distinción es patente en las disposiciones sobre el expendio de azogue. Frente a la adquisición al fiado por 6 meses de 2.000 libras que se reservaba a los azogueros potosinos, con devolución del principal por semanas, los trapicheros obtenían 300 libras, debiendo ser tres los mineros que se obligasen mancis.

21 Tandeter: Trabajo forzado y trabajo libre.... pág. 38.

22 Martiré, E.: Tolerancias, prevenciones y regulación participadora de los indios «capchas» de Potosi en la explotación del Cerro. «Estudios sobre politica indigenista española en América». «Terceras Jornadas Americanislas en la Universidad de Valladolid». 4 vols, Vol. III. Valladolid, 1977, págs. 291-303. 
munadamente a pagar el principal y los «correspondidos». Los mineros de afuera recibían al fiado, bajo fianzas y plazos, las mismas cantidades que los azogueros. Finalmente, los capchas podían adquirir cantidades no superiores a 100 libras, al contado o a crédito, estando exentos de «correspondidos» en el primer caso, por la incapacidad de que encontrasen fiadores y de que el importe pagado quedase como hipoteca de los «correspondidos», por lo que se aplicaba al precio del azogue («principal»). ${ }^{23}$

La expedición de guías y tornaguías, junto con la exigencia de «correspondidos», impuso un control sobre el tráfico de azogues y platas, sujeto siempre a pérdidas de consideración. El precio del azogue fue fijado en 73 ps. 3 rs. el quintal. Si consideramos la frecuente escasez de mercurio que sufría el virreinato, los elevados costes de los fletes, y la dilación en el abastecimiento, este precio resultaba muy favorable, más aún si tenemos en cuenta que poco tiempo después, en 1782 , no bajaría de 131 ps. 4 rs. ${ }^{24}$ La explicación inmediata hay que buscarla en la contrata firmada por José Antonio de Areche con Nicolás Sarabia, oportunista cuya acción de extracción de mineral de alta ley de los soportes y estribos de la mina de Huancavelica dio como resultado una abundancia ficticia que permitió reducir precios. ${ }^{25}$

En cuanto al proceso de requemo con vistas a liberar las «piñas» del azogue sobrante, las medidas de prueba y punición equiparaban a azogueros, trapicheros y capchas, si bien en el caso de éstos se efectuaba por cuenta propia en hornillos destinados al efecto, mientras que para los azogueros corría a cargo de la oficina de requemo de banco. ${ }^{26}$

Uno de los mayores cuidados del banco era el puntual pago a los mineros por las platas rescatadas, para que el laboreo de las minas no se viese detenido. Para ello, las platas se pagaban en el momento de ser entregadas y, si se descubrían mermas tras el requemo, se verificaban los descuentos la semana siguiente. Los

23 R.A.H. ML., toino VII. Testimonio de las Ordenanzas del Banco... Ord. 4.n. de 1782 .

24 A.G.I., Lima, 1.091, núm. 21. F.scobedo a Gálvez. Lima, 16 de diciembre

25 Palacio Alard. V.: El asiento de la Mina de Huancarelica en 1779. «Revista de Indias», núm. 18. Madrid, 1944, págś. 611-630.

26 R.A.H. MI.., tomo VII. Testimonio de las Ordenanzas..., tit. ¿.", Ord. 10.". 
mineros de afuera recibían las tres cuartas partes del valor de sus platas, reservándose la cuarta para respaldar las posibles faltas que se detectasen. ${ }^{27} \mathrm{La}$ desconfianza manifestada hacia los mineros extraños a la villa fue una constante. La ordenanza pretendía precaver el fraude, centrándose en aquellos casos en que la distancia podía favorecer la impunidad.

Se señalaba la obligatoriedad de satisfacer los pagos en moneda sellada, nunca en especie, poniendo fin a la práctica utilizada con anterioridad por los oficiales reales. La pena, pecuniaria en la primera vez, imponía la pérdida de oficio por reincidencia. ${ }^{28}$

El banco contaba con 70.000 ps. semanales para su giro, supliéndose fondos de la Casa de Moneda y cajas reales en caso de ser insuficiente. Los pagos de plata, labor de la tesorería, fueron sometidos a un estricto control con la expedición de boletas que el administrador entregaba al vendedor y eran verificadas por la contaduría. ${ }^{29}$

La entidad bancaria actuó como agente fiscalizador de todas las actividades, particularmente las que habían sido conflictivas durante las anteriores administraciones. Agilización de operaciones y custodia perfecta de los caudales fueron dos de las claves para ello. Disponibilidad de los fondos para el puntual servicio al público, pero impidiendo el derroche y los riesgos en transacciones de carácter individual.

La transformación de las «piñas» en barras de plata se regulaba a lo largo del título $3 .^{\circ}$. Adquiridas las «piñas» en sábado, para permitir su traslado al banco por los mineros sin interrupción de las labores extractivas, los lunes se procedía a su asentamiento en libros, fundición de piezas para detectar precio y calidad, y tasación en función de ambas, llevándose el martes a las cajas reales para, también por fundición, purificar la plata y comprobar que el administrador no había cometido errores.

Los gastos de afinación suponían 5 pesos por barra de 180 millcos. Los «bocados» no podían ser superiores a 4 ochavas y se eje-

27 Ibídem, Ord. $11 . "$.

28 Ibidem. Ord. 16."

29 Ibidem. Ords. 19.", 20.", 21.". 
cutaban tras la operación de repeso de las barras por el balanzario, proceso que se realizaba al día siguiente de la fundición. ${ }^{30}$

Estas operaciones tenían como finalidad cotejar lo realizado por el administrador y el ensayador en prevención de ilegalidades.

La capacidad de cada funcionario de denunciar ante el superintendente las irregularidades que pudieran observar en la actuación de los demás empleados, fue otro de los mecanismos de vigilancia establecidos ${ }^{31}$ y fue muy frecuente a lo largo de la administración colonial.

Tras la fundición de las barras, se procedía al pago de los reales derechos, una vez calculados por los oficiales reales en las boletas destinadas a ese fin: diezmo, $11 / 2 \%$ de cobos y derechos añadidos por fundición. Todo ello se pasaba a la tesorería del binco, donde se abonaba su importe en barras de suprema ley el mismo día del ensaye, para evitar «los desórdenes y riesgos a que en otro tiempo estubo (sic) expuesta la Real Hacienda por la dilación en satisfacerse». ${ }^{32}$ Los oficiales reales emitían los resguardos correspondientes como comprobantes del libro de importes que se llevaba al 'Tribunal de Cuentas. Finalmente, las barras se entregaban a la Casa de Moneda, debiendo las cie diezmos, por ser de Real Hacienda, ir exentas de los derechos de ensayadores, devolviéndose los «bocados» que se les hubiesen extraído. ${ }^{3 .}$

En prevención de actos dolosos en las actividades señaladas, la Casa de Moneda podía llevar a cabo nuevos ensayes para ajustar el valor de las barras con la tasación de las cajas reales y el banco, obviando aquellas inevitables diferencias que las distintas balanzas pudiesen arrojar, así como las derivadas de la extracción de «bocados» con que las barras llegaban a la Casa de Moneda. ${ }^{34}$

¿Qué margen de ganancia obtenía el banco de todas las operaciones propias de su intervención? ${ }^{35}$ De cada partida de 1.000 marcos de plata, y una vez realizadas las comprobaciones

30 Ibídem. Tít. 3.". Ords. 10.", 11.". 12.".

31 Ibidem. Ords. 2." y 14.".

32 Ibidem. Tít. 4.". Ords. 1." y 2.".

33 Ibidem. Ords. 3." 4." y $5 . "$

34 Ibidem. Ords. 7." y 8.".

35 Ibidem. Tit. 5.". 
mencionadas, el banco se reservaba una utilidad que oscilaba entre $1 / 2$ real y 1 real por marco, cifra con la que había de responder a los gastos derivados de cada labor y a la satisfacción de los sueldos de los empleados que, según la tabla adjunta, ascendían a 16.994 pesos anuales: ${ }^{36}$

Sueldos anuales que hoy satisface el Real Banco

Al Superintendente, 12 pesos diarios, desde la comisión del Sr. Tagle, que en el año no bisiesto importan: (c) ......... Al Administrador $\$ 4.388$.

A su Oficial plumario $\$ 3.100$ -

A dos fundidores, a 520 pesos cada uno... »1.040.-

$\mathrm{Al}$ ayudante de la fundición » 312.- $\gg$ 5.052.-

Al Contador

»2.000.-

A su Oficial primero

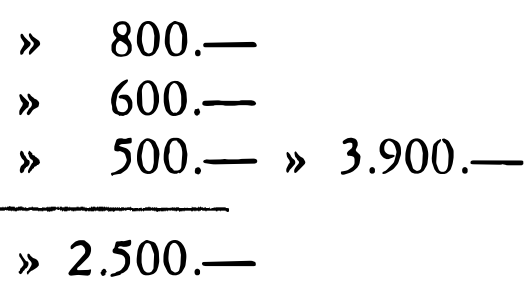

Al segundo

Al tercero

.........................

Al Tesorero

»2.500.-

A un Oficial suyo, a quien deben ayudar los fundidores de la dotación del Administrador, en el pagamento de las platas que se compran y demás ocurrencias

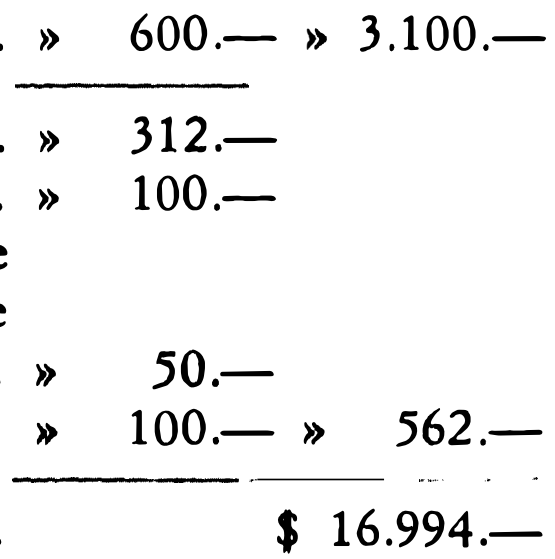

36 Cañete: Guia histórica, política, oeográfica..., pág. 140. 
Ciertos beneficios complementarios eran producto del cobro de «corridos» y «quebrados», es decir, los picos o cantidades que el banco no abonaba a los mineros cuando en sus ventas, una vez pesada la plata, superaban los 22 granos o eran superiores a una onza, en los primeros, o no llegaran a un marco (7 ps. 4 rs.) en los segundos. Debido a que esos excesos o mermas eran resultado de la calidad del mineral en su ley y beneficio, las condiciones no afectaban del mismo modo a los mineros, y así, mientras a los azogueros de Potosí (que obtenían más altos beneficios por sus platas) no se les reintegraba cantidad alguna por esos conceptos, los trapicheros, capchas y mineros de afuera, entregaban sólo $1 / 2$ onza cuando la partida que presentaban pasaba de 12 marcos, y $1 / 4$ cuando no alcanzase este peso.

Los «corridos» y «quebrados» se reducían de la totalidad de la partida semanal que cada minero presentaba en el banco, pesándose en tiradas no superiores a 100 marcos de plata.

\subsection{El Banco como institución proveedora}

$y$ entidad crediticia

La segunda función del Real Banco de San Carlos era la habilitación de insumos y concesión de créditos. ${ }^{37}$

Los auxilios que ofrecía a los mineros se organizaban a lo largo del título 6." de la ordenanza. Anualmente, el banco entregaba al gremio de azogueros de Potosí 50.000 pesos que podían aplicarse de la forma que consideraran más conveniente de acuerdo a sus intereses y sin intervención del superintendente. ${ }^{38}$ Esta disposición era novedosa, puesto que rompía con la fuerte dependencia que el gremio había soportado anteriormente respecto de los jueces conservadores y gobernadores locales, dotándolo así de un alto grado de autonomía.

37 Real Cédula de 1.0 de Octubre de 1776 al Virrey Guirior: Que los Virreyes y demás autoridades favorezcan al gremio de mineros como primeros artiflces y fundamento de la riqueza pública. $3 . a$ y $4 . a$.

38 R.A.H. ML., tomo VII. Testimonio de las Ordenanzas... Ords. 1.a, 2.a, 
La cantidad de la ayuda se prorrateaba por «cabezas de ingenio» entre todos los que en aquel momento los trabajasen, bien en propiedad $o$ en arrendamiento con mita, mientras que los ingenios sin mita recibían una tercera parte menos. La explicación de este diferente reparto estribaba en que el minero sin tanda de mitayos estaba en inferioridad de condiciones para la explotación $y$, consecuentemente, para la entrega de platas en el banco y la devolución de los créditos obtenidos. Pero, principalmente, carecía de la importante fuente de ingresos que aportaban los «rezagos», lo cual dificultaba su capacidad de hacer frente al elevado precio que había de pagar por el arrendamiento del «ingenio», lo cual podía empujarle, tarde o temprano, a abandonarlo. ${ }^{39}$

La ordenanza se orientó decididamente a la protección de los fondos del banco, especialmente en el tipo de créditos cuantiosos y a más largo plazo. El otorgamiento de nuevos auxilios no podría verificarse hasta el completo reintegro del anterior, obligación a la que quedaban suscritos los miembros del gremio por escritura de mancomunidad, condición «sine qua non» para la obtención del crédito y validación del arrendamiento de «ingenios». El banco no percibía intereses por los capitales que otorgaba en préstamo.

Semanalmente se procedía a la cobranza del auxilio al tiempo de vender la plata en el banco, mediante los descuentos correspondientes que efectuaba el administrador, imponiéndose multas aplicadas al fondo fijo en caso de dilación en la paga u otras prácticas en perjuicio del giro del banco. ${ }^{40}$

La utilización del auxilio en actividades extrañas a las minería se castigaba con la suspensión del mismo durante 4 años, pero manteniéndose el sometimiento a mancomunidad con los demás azogueros. ${ }^{4}$

De nuevo se dejaba sentir el peso de las pasadas irregularidades en el manejo de los fondos: los negocios ilegales de los of ciales reales involucrando los caudales del erario, la especulación

39 Tandeter: Propiedad y gestión en la minería potosina..., pág. 15.

40 R.A.H. ML., tomo VII. Testimonio de las Ordenanzas... Tit. 6.". Ords. 13.a, $14 .{ }^{n}, 15.4$ y $16 .{ }^{a}$.

41 Ibídem. Ord. 17.a. 
con los insumos, la cesión de acciones de la Compañía de Mineros en pago de deudas, los préstamos de grandes sumas a comerciantes totalmente desvinculados de la actividad minera.

Existían además una serie de auxilios extraordinarios, fijados en 1.000 pesos, para casos de urgencia en la paga de la mita y mano de obra mingada, o por deterioros materiales. Como garantía habían de depositarse «alajas (sic) de oro, o plata, que en su peso tengan más valor de dicha cantidad ...», ${ }^{42}$ debiendo cobrarse en 4 meses y siendo libre la forma de pago que, de incumplirse, daba al banco la facultad para vender las «alajas» depositadas, aplicando las de plata a la chafalonía, y las de oro a las cajas reales para pasarlas a la Casa de Moneda, corriendo todos los gstos de ensaye, reales derechos, etc., a cargo del dueño .

El tratamiento conferido a los mineros fue distinto según su categoría. Los trapicheros potosinos carecían de auxilio (por no estar adscritos al gremio) y tan sólo se les ofrecían 200 pesos de ayuda, siempre que aportasen el respaldo de prendas o fiadores. El plazo de devolución se fijó en 4 meses, y estaban sometidos a las mismas responsabilidades que los azogueros. Siendo los trapicheros sujetos pobres, con una escasa producción, era difícil que encontraran el aval que se les exigía, por lo que en este punto de la ordenanza se presenta como prenda de adorno en un sistema de reforma que, aparentemente igualitario y globalizador, se dirigía a favorecer a los grandes explotadores y propietarios de minas, marginando al pequeño minero.

Se trató de un reformismo de élite, reservado a los azogueros de cierto peso económico y social, cuyas actividades iban a producir una rentabilidad de la que la Real Hacienda sería la beneficiaria directa. El minero sin solvencia económica permaneció sometido a los abusos de los «aviadores». El banco nunca pretendió eliminarlos, sino competir con ellos en la oferta de ventajas, ganarles la partida por la exclusividad, arrebatándoles los mejores clientes y dejando en sus manos las operaciones de más alto riesgo y escaso rendimiento.

42 Ibidem. Ords. 18.", $19 .{ }^{a}$ y $20 .^{n}$. 
Los mineros de afuera, además de las fianzas y la sujeción a los plazos establecidos, debían presentar una certificación del corregidor de la provincia en la que se declarase que no había en ella banco, y otra del contador del banco de haber traído en otrils ocasiones no menos de 500 marcos de plata en «piña». Los capchals fueron absolutamente ignorados en esta normativa sobre auxilios.

Esta práctica discriminatoria desvirtuó la esencia de la institución: el fomento general del minero.

\subsection{La promoción de la lécnica extractiva}

Finalmente, en relación a la tercera función del banco como organismo potenciador de medidas de fomento, se le hizo cargo expresamente de las obras del «socabón» (sic) de Potosí, fijándose una cantidad no superior a 20.000 pesos anualmente para hacer frente a los gastos y reservándose los minerales de plata que en su trazado pudiesen aparecer.

Los libramientos del fondo fijo de 200.000 pesos anuales se llevarían a cabo bajo supervisión directa del superintendente y a través de un complejo sistema para precaver las malversacioncs que se habían experimentado. ${ }^{43}$

Recibos, boletos y otros documentos servirían de justificantes de los balances, estados «mensales» (sic), cuentas y asiento de liss mismas en los libros de Contaduría, Tesorería y Administración. Los sobrantes del giro debían pasar anualmente a las cajas reales. Ejemplares duplicados de toda la labor contable se enviarían al Tribunal de Cuentas para su comprobación. ${ }^{44}$

Teniendo en cuenta el intento de simplificación en las tareas de contabilidad que se pondría en práctica, aunque con éxito discutible, poco tiempo después, ${ }^{45}$ no deja de sorprender el farragoso

43 Ibídem. Tit. 7.".

44 Ibídem. Tít. 9.".

45 R.A.H. ML., tomo LXXVIII, fols. 525-563. Mélodo de Cuenta y Razón por Partida Doble para la Real Hacienda en las Indias. Año de 1784. A.G.l., Lima, 1.437, núm. 860. El Superintendente... sobre el modo de hacer los asientos en los Libros... Lima, 22 de febrero de 1787. A.G.I., Lima, 612. Comunicación de Escobedo. Año de 1787. R.A.H. MI., tomo CXIV, fols. 153-154. Informe de Valdés. Buenos Aires, 1788. 
e intrincado sistema fijado para las del banco de la Villa de Potosí. El administrador, fuera de las cuentas del giro semanal del banco, llevaba a su cargo 9 libros, 4 el tesorero y 10 el contador, quien además debía comprobar las cuentas y libros de las otras oficinas. ${ }^{46}$

Los restantes títulos de la ordenanza fijaban detalladamente las obligaciones, facultades y sueldos de los empleados del banco.

El reglamento para el Real Banco de San Carlos de la Villa de Potosí recibió la aprobación del monarca por real orden fechada en San Ildefonso el 24 de agosto de 1782, comunicada por el ministro de Indias al nuevo gobernador de Potosí, don Juan del Pino Manrique, en 17 de enero de $1783 .{ }^{47}$

\section{Concilusiones}

Aparentemente, la nueva normativa contaba con los mejores auspicios para restablecer el orden y concierto en las actividades del centro minero. Sin embargo, aunque las condiciones generales mejoraron, los cambios introducidos no llegaron a transformar la estructura:

«...en una coyuntura tan desfavorable, la creación de un banco de crédito minero en Potosí no podía sanear la economía vacilante y oprimida de la industria de la platan. ${ }^{48}$

46 R.A.H. ML., tomo VII. Testimonio de las Ordenanzas... Tit. 9.0.

Administrador: 1, azogueros de Potosí; 2. Trapicheros: 3. capchas; 4. chafalonia; 5-8. provincias de Chayanta, Porco. Chicas, Lipes y Atacama; 9. Pundiciones.

Tesorero: 1. diario de partidas de rescate; 2 . libro de sobrantes del fondo; 3. libro de fondos y su movimiento anual; 4. libro de gastos del socavón.

Contador: 1. diario de partidas de rescate; 2. libro de cuentas semanales; 3. libro de Pondos: 4 . libro de Pundiciones; 5 . libro de deudores por auxilios recibidos; 6. libro de auxilios anuales y beneficiarios; 7. libro de auxilios menores; 8. libro duplicado de los gastos del socavón; 9. libro de ley y peso de las barras fundidas en Caxas Reales y vendidas en la Casa de Moneda; 10, libro de Provisiones Reales y Superiores Ordenes: 11. inventario general de todo el fondo útil e inútil del Banco después de la incorporación, con deudas pendientes y pagas que se vayan cubriendo.

47 Ibidem, fol. 171.

48 Helmer, M.: Mineurs allemands a Potosi: L'expedition Nordenflycht (17881798). «La Minería Hispana...», vol. I. pág. 525. 
Tanto Escobedo como Pino Manrique, que habían calificado el establecimiento como «utilísimo» y como pilar del sostenimiento de la Villa, no ocultaron, sin embargo, su desasosiego ante las nuevas circunstancias, temiendo que las regulaciones «no serían suficiente». ${ }^{49}$

El estallido de la rebelión de Túpac Amaru, el desequilibrio en la dotación de mano de obra mitaya, las sequías y la resistencia opuesta por el inmovilismo local, desembocaron en la adopción de prácticas extrañas al espíritu de la ordenanza que, inicialmente consideradas «excepciones» de carácter extraordinario y temporal, terminarían haciéndose permanentes. ${ }^{50}$

Años después, Jorge Escobedo informaba de la grave situación del reino:

"Estas provincias están aniquiladas por los pasados alborotos; ellos y la guerra de Europa han hecho un paréntesis doloroso a el comercio, que sentirá después las quiebras; El Erario está des. truido... no hay otro camino que el de la Minería protegida y auxiliada...... ${ }^{51}$

Parece indudable que su gestión fue encaminada al establecimiento de un sistema típicamente borbónico que, basado en el orden de las cuentas, el rígido control del funcionariado y la consecución de ingresos a la Real Hacienda, habría de funcionar como entidad modélica en el virreinato.

Entre 1780 y 1783 se llevaron a cabo los trámites para trassplantar el sistema a Chile. Escobedo fijó las pautas para adaptar y aplicar las ordenanzas dictadas para Potosí. El 4 de diciembre de 1794, en consejo de tres salas, se aprobó la impresión de las ordenanzas, una vez redactadas por Pedro Vicente Cañete las «Adicciones» (sic) que se le encargaron, haciendo universal para

49 Buechler, R. M.: The Mining Society of Potosi. 1776-1810. Syracuse University, 1981, pág. 53 .

50 Ibidem. cap. 1.

51 A.G.I., Lima, 1.096, núm. 50. Escobedo a Gálvez. Lima, 16 de marzo de 1786. 
todas las minas del virreinato el nuevo reglamento del banco de Potosí. 52

El virreinato peruano, en la década de los 90, asistiría a la proliferación de bancos de rescate (Huarochirí, Hualgayoc, Lucanas, Huantajaya, Lima) siguiendo la pauta establecida en Potosí pionera en la implantación de tales organismos. Este hecho evidencia las firmes esperanzas depositadas en ellos como sistema de freno para salvar al minero de su dependencia del círculo mercantil, esperanzas que, en el caso peruano, se vieron frustradas. ${ }^{53}$

Los implantados en Nueva España, aunque tardíos, fueron, quizás, los más exitosos. ${ }^{54}$

En la Villa de Potosí, la pervivencia del Banco de San Carlos durante las últimas décadas de la época colonial, y su transformación en 1825 en Banco Nacional de Rescates, parecen confirmar, cuando menos, que alguna utilidad reportaba la institución. A pesar de ello, la misión Weber, en 1792, informaba con desencanto sobre la situación de la minería potosina:

"Un conjunto de desórdenes, desarreglo, abusos... y por estos graves defectos a pesar de las riquezas de que se hallan rodeadas (estas provincias), nunca ha podido alcanzar la minería en estc país un estado floreciente). 55

Bajo la apariencia de una bien fundamentada normativa, los problemas estructurales pervivieron sin cambios de consideración.

\section{Serena Fernández Alonso}

52 R.A.H. ML., tomo CXVII, fols. 283-284.

53 Molina Martínez, M.: El Real Tribunal de Minería de Lima (1785.1821). Diputación Provincial de Sevilla. Sevilla, 1986.

54 Mariscal Romero: Los Bancos de Rescate.... pág. 317.

55 R.A.H. ML., tomo X, fols. 202-214. Informe del estado de la minería de las Provincias del Río de la Plata (...) remitido por mano del Sr. Arredondo (...) Virrey y Capitán General (...) por el segundo Director de la Expedición Mineralógica D. Juan D. de Weber. Polosí, 25 de septiembre de 1792. 